\title{
The Effect of Citrate and Phosphocitrate On Struvite Spontaneous Precipitation
}

\author{
Aikaterini N. Kofina, ${ }^{\dagger \ddagger}$ Konstantinos D. Demadis, ${ }^{\S}$ and Petros G. Koutsoukos ${ }^{*}, \dagger$ \\ Department Of Chemical Engineering, University Of Patras, Patras, GR-26504, Greece, Institute of \\ Chemical Engineering and High Temperature Chemical Processes, Foundation for Research and \\ Technology Hellas, P.O. Box 1414, Patras, GR-26500, Greece, and Crystal Engineering, Growth and \\ Design Laboratory, Department of Chemistry, University of Crete, \\ P.O. Box 2208, Voutes, Heraklion, GR-71003, Greece
}

Received June 24, 2006; Revised Manuscript Received July 26, 2007

\begin{abstract}
The effect of citrate and phosphocitrate ions on the spontaneous precipitation of magnesium ammonium phosphate hexahydrate $\left(\mathrm{MgNH}_{4} \mathrm{PO}_{4} \cdot 6 \mathrm{H}_{2} \mathrm{O}\right.$, struvite $)$ at $\mathrm{pH} 8.50$ and $25{ }^{\circ} \mathrm{C}$ was investigated at conditions of constant solution supersaturation. The supersaturated solutions were prepared in synthetic wastewater. The presence of citrate and phosphocitrate in the working solutions showed reduction of the initial rates of struvite precipitation when compared with solutions in their absence. The parabolic dependence of the rates of precipitation on the relative solution supersaturation suggested a surfacediffusion-controlled mechanism. Presence of citrate and phosphocitrate in the supersaturated solutions at concentration levels from 1 to $10 \mu \mathrm{M}$ resulted in a drastic increase in induction times. The presence of citrate and phosphocitrate inhibited struvite precipitation up to $75-80 \%$. The reduction of precipitation rates was related to additive concentration following an expression suggested by the kinetic Langmuir-type adsorption model. The affinity constant calculated for citrate $\left(8.2 \times 10^{5}\right)$ was considerably higher than the respective value for phosphocitrate $\left(0.6 \times 10^{5}\right)$. Finally, it should be noted that the morphology of the prismatic, elongated struvite crystals precipitated in the presence of citrate and in the presence of phosphocitrate showed differences only in size.
\end{abstract}

\section{Introduction}

Struvite or magnesium ammonium phosphate hexahydrate $\left(\mathrm{MgNH}_{4} \mathrm{PO}_{4} \cdot 6 \mathrm{H}_{2} \mathrm{O}\right)^{1}$ is a crystalline salt, that may be used as either a fertilizer or raw material for the production of phosphorus. ${ }^{2}$ Very often, struvite is found as a constituent of scale deposits on pipe walls and other mechanical equipment surfaces of the wastewater treatment industry, such as pumps and aerators. Remediation, most of the time, is costly and timeconsuming. Such problems have been reported at several wastewater treatment units. ${ }^{3,4}$ The use of inhibitors for scale prevention is widely practiced and involves addition of compounds inhibiting a specific type of scale deposits at very low concentrations. ${ }^{5}$

Besides scale deposits, struvite is also found in biologically important minerals like urinary stones. ${ }^{6}$ Urinary stone formation is a major example of pathological mineralization. The most abundant minerals encountered in urinary stones are carbonated apatite, brushite, struvite, calcium oxalate monohydrate, calcium oxalate dihydrate, and uric acid. ${ }^{7}$ Biological mineralization is often the cause of significant medical problems. It has been shown that the presence of phosphorylated carboxylic acids may act as inhibitors of this type of undesired mineral deposits. ${ }^{8}$

When the ion activities of $\mathrm{Mg}^{2+}, \mathrm{NH}_{4}{ }^{+}$, and $\mathrm{PO}_{4}{ }^{3-}$ in solution exceed the respective solubility product, spontaneous precipitation of struvite is possible. The extent of struvite precipitation and the characteristics of the precipitating solid depend on the solution $\mathrm{pH}$, supersaturation, temperature, and the presence of foreign ions. Citrate and phosphocitrate have been shown to be effective inhibitors of the crystal growth of several sparingly soluble salts including hydroxyapatite, ${ }^{9}$ octacalcium phosphate, ${ }^{10}$

\footnotetext{
* Corresponding author. E-mail: pgk@iceht.forth.gr.

University Of Patras.

* Foundation for Research and Technology Hellas.

${ }^{\S}$ University of Crete.
}

Scheme 1. Citric acid (left) and phosphocitric acid (right) in their fully protonated form

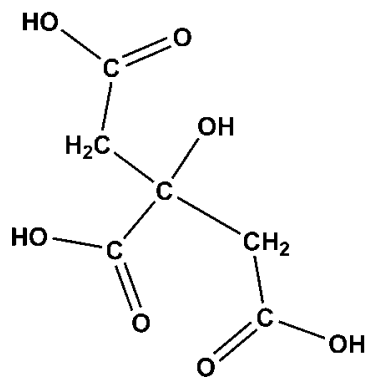<smiles>O=C(O)CC(CC(=O)O)(OP(=O)(O)O)C(=O)O</smiles>

calcium pyrophosphate, ${ }^{11}$ calcium oxalate, ${ }^{12}$ calcite, and gypsum. ${ }^{13}$ Phosphocitrate was reported to inhibit in vivo the formation of struvite. ${ }^{14}$ Crystal growth studies and molecular modeling results indicate strong affinity of phosphocitrate to (101) faces of struvite. ${ }^{15}$ Wierzbicki et al. suggested that gradual addition of phosphocitrate induced morphology changes that reflect the interactions between the inhibitor and the crystal surfaces at a molecular level, but no change was observed in the presence of citrate. ${ }^{15}$

In the present work, we have investigated the effect of the presence of citrate and phosphocitrate ions in the spontaneous precipitation of struvite from synthetic wastewater (SWW) solutions supersaturated with respect to struvite at $25{ }^{\circ} \mathrm{C}$ and $\mathrm{pH} 8.50$ at conditions of constant solution supersaturation. These additives possess several similarities, as well as significant structural differences, as shown in Scheme 1. To examine the effect of the presence of the two ions in the supersaturated solutions, two sets of experiments were done: In the first set of experiments, the additive concentration was kept constant while the solution supersaturation varied. In the second set of experiments, the effect 
Table 1. Composition of SWW Used for the Supersaturated Solutions Preparation

\begin{tabular}{lc}
\hline component & concentration $(\mathrm{M})$ \\
\hline glucose & $5.17 \times 10^{-4}$ \\
$\mathrm{NaHCO}_{3}$ & $17.86 \times 10^{-3}$ \\
$\mathrm{NaCl}$ & $1.00 \times 10^{-2}$ \\
$\mathrm{NaNO}_{3}$ & $5.88 \times 10^{-3}$ \\
$\mathrm{Na}_{2} \mathrm{SO}_{4}$ & $1.20 \times 10^{-2}$
\end{tabular}

Table 2. Experimental Conditions: Concentration, $\mathrm{pH}$, Supersaturation, Relative Supersaturation, Induction Time $\tau$, and initial growth rates, $R$, for the Spontaneous Precipitation of Struvite in SWW in the Presence of $1 \mu \mathrm{M}$ Citrate

\begin{tabular}{cccccc}
\hline $\begin{array}{c}C_{\mathrm{Mg}}=C_{\mathrm{NH}_{4}}=C_{\mathrm{PO}_{4}} \\
\left(\times 10^{-3} \mathrm{M}\right)\end{array}$ & $\mathrm{pH}$ & $\Omega$ & $\sigma$ & $\tau(\mathrm{s})$ & $\begin{array}{c}R\left(\times 10^{-6}\right. \\
\mathrm{mol} / \mathrm{min})\end{array}$ \\
\hline 4.10 & 8.51 & 5.6364 & 0.7796 & 255 & 34.7 \\
4.00 & 8.57 & 5.5207 & 0.7674 & 345 & 16.7 \\
4.00 & 8.51 & 5.2966 & 0.7431 & 875 & 9.00 \\
3.90 & 8.54 & 5.1880 & 0.7311 & 1195 & 3.7 \\
3.80 & 8.54 & 4.8640 & 0.6943 & 1335 & 3.5 \\
3.80 & 8.53 & 4.7973 & 0.6865 & 1725 & 3.2 \\
3.70 & 5.56 & 4.6666 & 0.6711 & 3155 & 2.0 \\
3.60 & 8.58 & 4.5394 & 0.6557 & 3585 & 1.7
\end{tabular}

of increasing additive concentration was examined at a given supersaturation value.

\section{Experimental Section}

All experiments were done at $25{ }^{\circ} \mathrm{C}$ in a $250 \mathrm{~mL}$ thermostated, magnetically stirred double-walled Pyrex vessel. The temperature was kept constant by circulating water from a constant temperature water bath. A constant flow of water vapor saturated nitrogen was maintained over the solution throughout the precipitation process to avoid atmospheric carbon dioxide intrusion. A combination glass/saturated calomel electrode standardized before and after each experiment with standard buffer solutions was used for the solution $\mathrm{pH}$ measurements and the precipitation control. The experiments were done at least in triplicate for the assessment of repeatability.

Stock solutions of magnesium sulfate heptahydrate $\left(\mathrm{MgSO}_{4} \cdot 7 \mathrm{H}_{2} \mathrm{O}\right)$, dihydrogen ammonium phosphate $\left(\mathrm{NH}_{4} \mathrm{H}_{2} \mathrm{PO}_{4}\right)$, and citric acid $\left(\mathrm{C}_{6} \mathrm{H}_{8} \mathrm{O}_{7}\right)$ were prepared from corresponding commercially available (Merck, reagent-grade), crystalline solids using triply distilled water. In this paper, the term phosphocitrate (PC) is used with no specific reference to proton content, unless otherwise noted. The synthesis and characterization of sodium phosphocitrate as the tetrakis-deprotonated $\mathrm{Na}_{4}$ (HPC) $\cdot 3 \mathrm{H}_{2} \mathrm{O}$ was performed according to a modified literature procedure. ${ }^{9 b, 17}$ Reagent grade chemicals and triply distilled water were used to prepare the synthetic wastewater solution (SWW). The chemical composition of synthetic wastewater ${ }^{18}$ is shown in Table 1 and was used as a solvent for the preparation of the supersaturated solutions. The composition of test solutions was selected on the basis of the most common chemical components of municipal wastewater. The organic content of SWW solutions was simulated with glucose. Glucose is not anticipated to interfere with the precipitation process and does not sequester constituent ions of the precipitating salt.

$\mathrm{Na}_{2} \mathrm{SO}_{4}$ was included as a component in synthetic wastewater (SWW) solution in order to maintain ionic strength during the titrants addition needed by the constant supersaturation methodology.

All stock solutions of the salts used and the SWW solution were filtered through membrane filters $(0.22 \mu \mathrm{m}$ Millipore $)$ before the experiment. Magnesium stock solution was standardized with EDTA titrations. Sodium hydroxide solutions, $\mathrm{NaOH}$ (Merck, Titrisol), were standardized against potassium hydrogen phthalate solutions, $\mathrm{C}_{8} \mathrm{H}_{5} \mathrm{KO}_{4}$, prepared fresh from the respective crystalline solid (Merck, reagentgrade) and dried overnight at $105{ }^{\circ} \mathrm{C}$. Ammonium phosphate stock solution was standardized with potentiometric titrations with standard sodium hydroxide solution.

In all supersaturated solutions of the present work, a 1:1:1 total magnesium $\mathrm{Mg}_{\mathrm{t}}$ :total ammonium $\left(\mathrm{NH}_{4}\right)_{\mathrm{t}}$ :total phosphate $\left(\mathrm{PO}_{4}\right)_{\mathrm{t}}$ stoichiometry was adopted. The supersaturated solutions were prepared in the reactor by rapidly mixing proper volumes of synthetic wastewater
Table 3. Experimental Conditions: Concentration, $\mathbf{p H}$, Supersaturation, Relative Supersaturation, Induction Time $\boldsymbol{\tau}$, and Initial Growth Rates $\boldsymbol{R}$, for the Spontaneous Precipitation of Struvite in SWW in the Presence of $1 \mu \mathrm{M}$ Phosphocitrate

\begin{tabular}{cccccc}
\hline $\begin{array}{c}C_{\mathrm{Mg}}=C_{\mathrm{NH}_{4}}=C_{\mathrm{PO}_{4}} \\
\left(\times 10^{-3} \mathrm{M}\right)\end{array}$ & $\mathrm{pH}$ & $\Omega$ & $\sigma$ & $\tau(\mathrm{s})$ & $\begin{array}{c}R\left(\times 10^{-6}\right. \\
\mathrm{mol} / \mathrm{min})\end{array}$ \\
\hline 4.10 & 8.52 & 5.7147 & 0.7878 & 385 & 9.4 \\
4.00 & 8.52 & 5.3703 & 0.7512 & 510 & 6.9 \\
3.80 & 8.51 & 4.8752 & 0.6956 & 675 & 5.1 \\
3.80 & 8.54 & 4.5498 & 0.6570 & 930 & 3.7 \\
3.70 & 8.53 & 4.4874 & 0.6494 & 1224 & 2.8 \\
3.60 & 8.52 & 4.1209 & 0.6032 & 2025 & 1.8 \\
3.50 & 5.55 & 4.0086 & 0.5885 & 3084 & 0.8 \\
3.40 & 8.58 & 3.8725 & 0.57036 & 3660 & 0.6
\end{tabular}

solution, aqueous solution of citrate or phosphocitrate, and $\mathrm{NH}_{4} \mathrm{H}_{2} \mathrm{PO}_{4}$. Next, the solution $\mathrm{pH}$ was adjusted to 8.50 by the addition of standard solution of sodium hydroxide as needed, followed by the addition of the accurately measured volume of stock magnesium sulfate solution. Finally, the solution $\mathrm{pH}$ was readjusted to 8.50 as needed.

The precipitation reaction may be described by eq 1

$$
\mathrm{Mg}^{2+}+\mathrm{NH}_{4}^{+}+\mathrm{H}_{2} \mathrm{PO}_{4}{ }^{-} \Leftrightarrow \mathrm{MgNH}_{4} \mathrm{PO}_{4} \cdot 6 \mathrm{H}_{2} \mathrm{O} \downarrow+2 \mathrm{H}^{+}
$$

According to eq 1, during the precipitation of struvite, protons are released into the solution. A solution $\mathrm{pH}$ drop exceeding $0.005 \mathrm{pH}$ units triggered the addition of titrant solutions from two computer-driven, motorized, electrical burettes: The titrant solutions consisted of the stock solutions of magnesium and phosphate, the SWW solution as solvent, the additive (citric acid or sodium phosphocitrate), and $\mathrm{NaOH}$ solution as needed to adjust the working solution $\mathrm{pH}$. The concentrations were calculated from the mass balance equations for all ions. ${ }^{19}$

From the recorded traces of the titrant addition as a function of time, the initial rates were calculated from the slope of the curve at $t \rightarrow 0$. The time lapsed between the preparation of the supersaturated solutions (including $\mathrm{pH}$ adjustment) and the first addition of the titrant solution concomitant with the change in $\mathrm{pH}$ value because of the struvite precipitation was taken as the induction time, $\tau$.

During the incubation period and the subsequent precipitation in the supersaturated solutions, samples were withdrawn and filtered through $0.22 \mu \mathrm{m}$ membrane filters. The filtrates were analyzed for magnesium by atomic absorption spectrometry (Perkin-Elmer AAnalyst 300) and for phosphate spectrophotometrically (Hitachi U-2001 UV/Vis) by the Vanado-molybdate complex formation method. ${ }^{19}$ At the end of each experiment, the solids were collected on the $0.22 \mu \mathrm{m}$ filter, dried at room temperature, and characterized by powder X-ray diffraction (Philips 1830/40) and scanning electron microscopy (SEM, JEOL JSM 5200, and LEO VP-35 FEM). Specific surface area measurements were done by $\mathrm{N}_{2}$ adsorption (BET method, Micromeritics, Gemini III 2375). The electrophoretic mobility of struvite precipitates suspended in saturated solutions in the presence of different concentrations of citrate and phosphocitrate ions were measured with Zetasizer 5000 (Malvern). The samples for the zeta-potential measurement of struvite were prepared by suspending crystals of precipitated struvite in solutions saturated with respect to struvite to avoid dissolution. The weight fraction suspended was kept at $<0.1 \%$ (w/w), allowing for the appropriate beam obscuration required for the measurements. Each measurement was the average of 5 cycles that lasted for time periods sufficiently fast to avoid sedimentation of the suspended crystals. The reported values are the mean of triplicate measurements. The reproducibility of the measured values was better than $3 \%$. The electrophoretic mobility measured was converted into zeta-potential using the Smoluchowski equation, without corrections because of the relatively high ionic strength of the suspensions in combination with the large size of the suspended particles.

\section{Results and Discussion}

The driving force for the formation of struvite in aqueous supersaturated solutions is the difference between the chemical potential, $\Delta \mu$, of the salt in the supersaturated solution $\mu_{\mathrm{s}}$ and the corresponding value at equilibrium, $\mu_{\infty}$. Assuming that the 


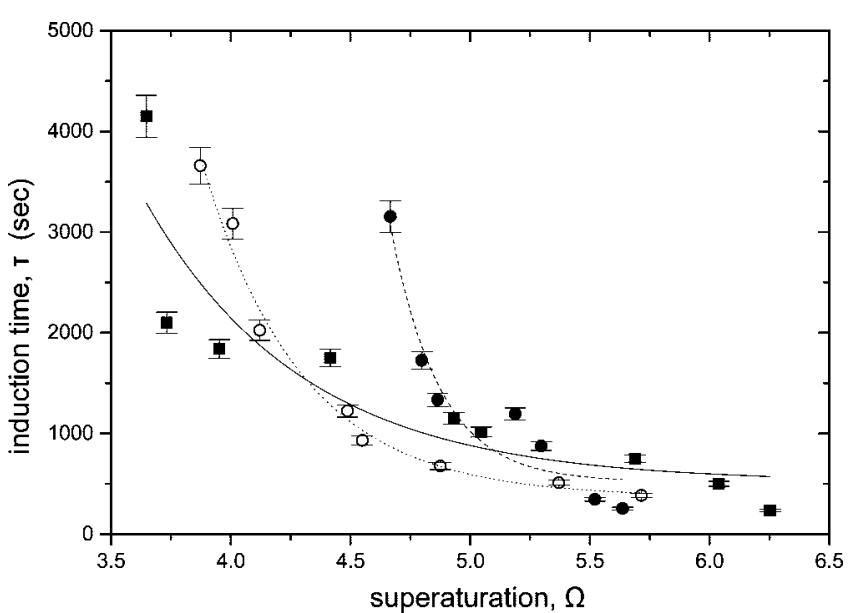

Figure 1. Stability diagram for struvite in synthetic wastewater: In the absence of additive ( $\square$ ), in the presence of $1 \mu \mathrm{M}$ citrate $(\bullet)$, and in the presence of $1 \mu \mathrm{M}$ phosphocitrate $(O)$.

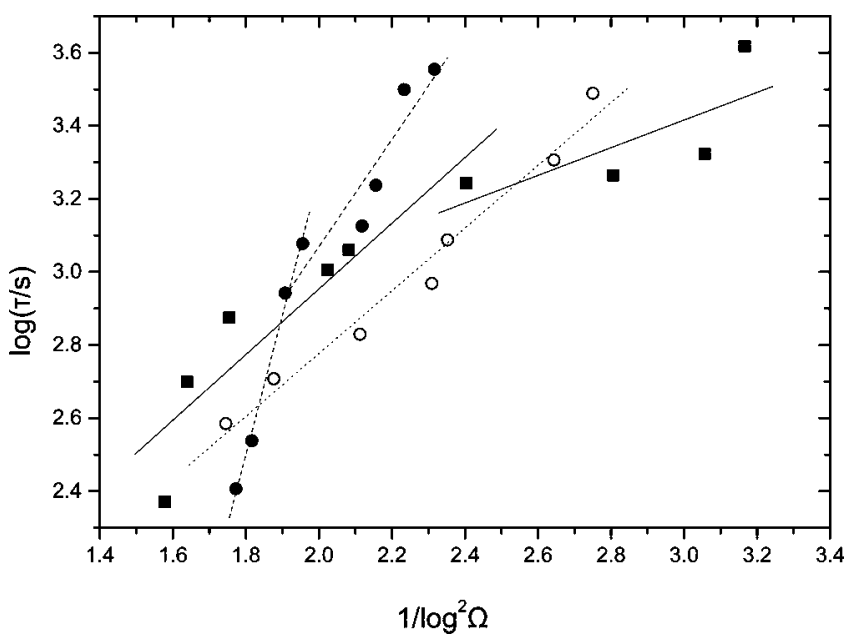

Figure 2. Plot of the logarithm of induction time preceding the spontaneous precipitation of struvite in SWW as a function of (log $\Omega)^{-2}$ : in the absence of additive $(\mathbf{\square})$, in the presence of $1 \mu \mathrm{M}$ citrate $(\bullet)$, and in the presence of $1 \mu \mathrm{M}$ phosphocitrate $(\bigcirc)$.

chemical potentials of the standard states in the supersaturated solution and at equilibrium are equal the difference in chemical potentials is

$$
\Delta \mu=k T \ln \frac{\left(a_{\mathrm{Mg}^{2}+} \cdot a_{\mathrm{NH}_{4}^{+}} \cdot a_{\mathrm{PO}_{4}{ }^{3-}}\right)_{s}^{1 / 3}}{\left(a_{\mathrm{Mg}^{2}} \cdot a_{\mathrm{NH}_{4}^{+}} \cdot a_{\mathrm{PO}_{4}{ }^{3-}}\right)_{\infty}^{1 / 3}}=-\frac{k T}{3} \ln \Omega
$$

where $k$ is the Boltzmann's constant and $T$ the absolute temperature. The logarithmic term is the supersaturation ratio $\Omega$, given by

$$
\Omega=\frac{a_{\mathrm{Mg} 2^{+}} \cdot a_{\mathrm{NH}_{4}^{+}} \cdot a_{\mathrm{PO}_{4}^{3-}}}{K_{s}^{0}}
$$

where $K_{\mathrm{s}}^{0}$ is the thermodynamic solubility product of struvite. The relative supersaturation $\sigma$ was defined as

$$
\sigma=\Omega^{1 / 3}-1
$$

The activities of the ionic species in solution and the supersaturation ratio $\Omega$ were calculated by the MINEQL+ chemical equilibrium modeling software ${ }^{20}$ taking into account

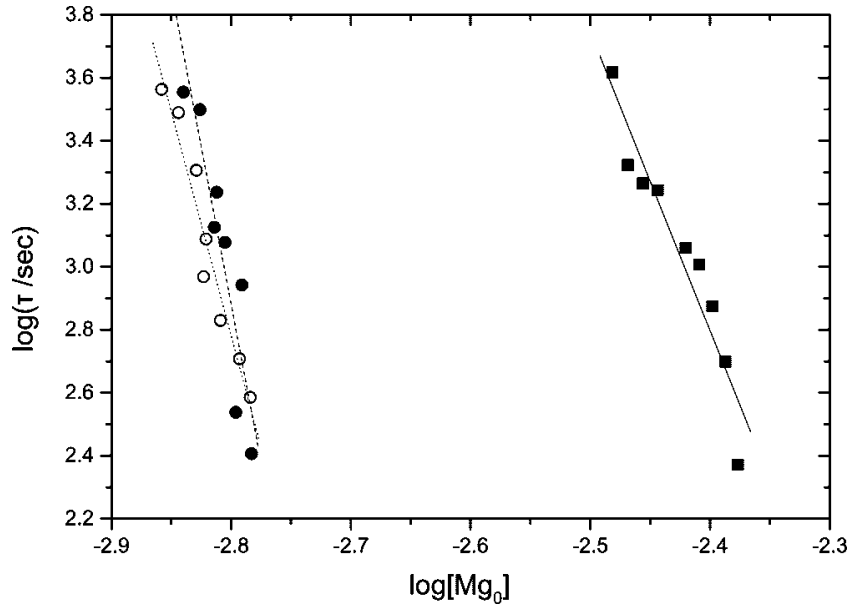

Figure 3. Plot of the logarithm of the induction times measured as a function of the initial magnesium concentration in SWW: in the absence of additive ( $\mathbf{\square})$, in the presence of $1 \mu \mathrm{M}$ citrate $(\bullet)$, and in the presence of $1 \mu \mathrm{M}$ phosphocitrate $(\mathrm{O})$.

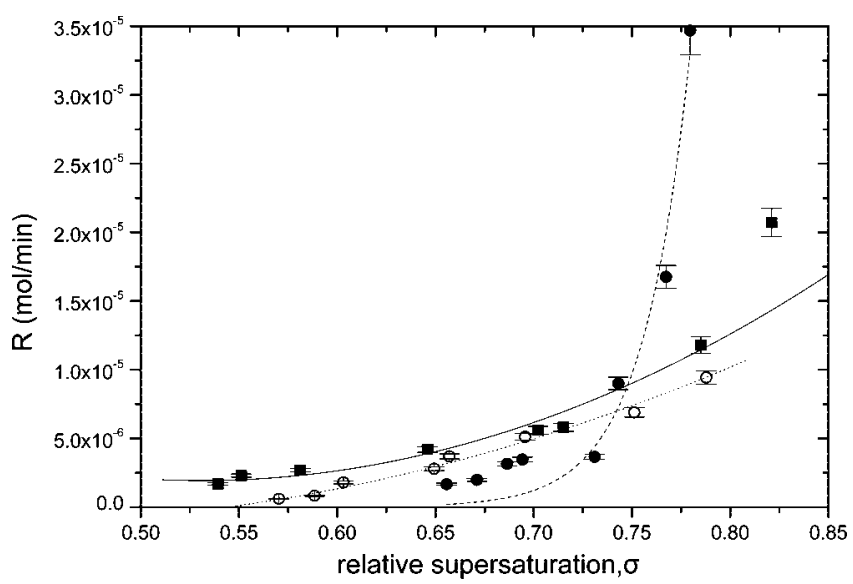

Figure 4. Plot of the rates of struvite precipitation as a function of the solution supersaturation in solution: in the absence of additive ( $\square$ ), in the presence of $1 \mu \mathrm{M}$ citrate $(-)$, and in the presence of $1 \mu \mathrm{M}$ phosphocitrate $(\bigcirc)$.

Table 4. Experimental Conditions: Additive Concentration, Induction Time $\tau$, Initial Growth Rates $R$, and Relative Inhibition

\begin{tabular}{|c|c|c|c|}
\hline$C_{\text {additive }}\left(\times 10^{-6} \mathrm{M}\right)$ & $\tau(\mathrm{s})$ & $R\left(\times 10^{-6} \mathrm{~mol} / \mathrm{min}\right)$ & inhibition \\
\hline 0.00 & 1150 & 5.6 & \\
\hline \multicolumn{4}{|c|}{ Citrate } \\
\hline 1.00 & 1335 & 3.46 & 38 \\
\hline 2.50 & 1695 & 2.34 & 58 \\
\hline 5.00 & 2100 & 1.73 & 69 \\
\hline 7.50 & 2645 & 1.54 & 73 \\
\hline 10.0 & 2915 & 1.43 & 74 \\
\hline \multicolumn{4}{|c|}{ Phosphocitrate } \\
\hline 1.00 & 675 & 5.11 & 9 \\
\hline 2.50 & 945 & 4.74 & 15 \\
\hline 5.00 & 1325 & 3.76 & 33 \\
\hline 7.50 & 1775 & 2.22 & 60 \\
\hline 10.0 & 2275 & 1.18 & 79 \\
\hline
\end{tabular}
for the Spontaneous Precipitation of Struvite in SWW at pH 8.50, $25^{\circ} \mathrm{C}$, and Supersaturation $\Omega=4.8640, \sigma=0.6943$

all equilibria involved together with the mass balance and electroneutrality conditions.

The experimental conditions and the results obtained from the first set of experiments, done at constant supersaturation in 


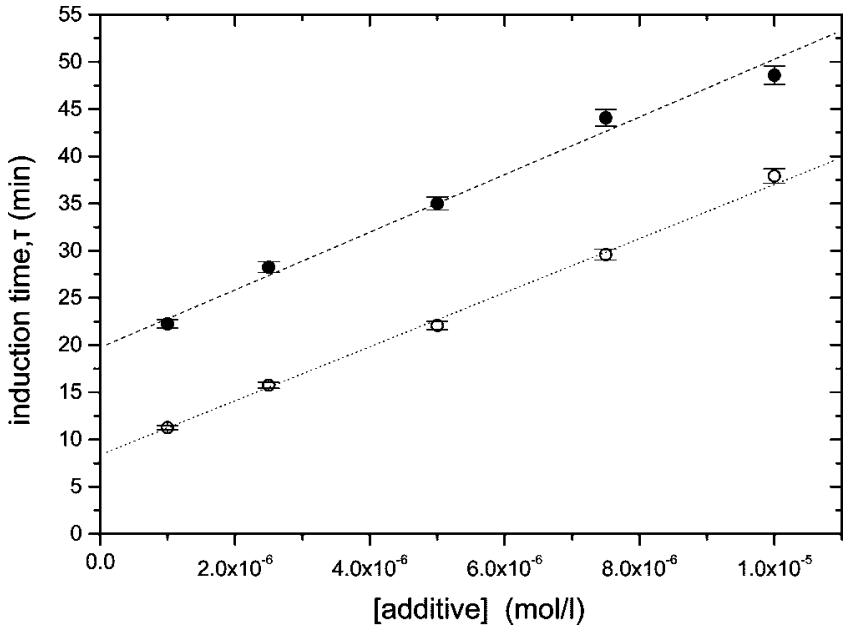

Figure 5. Dependence of the induction time preceding spontaneous precipitation of struvite in synthetic wastewater solutions on the additive concentration, $\mathrm{pH} 8.50,25^{\circ} \mathrm{C}$, and supersaturation $\Omega=4.864, \sigma=$ 0.694: in the presence of citrate $(\mathbf{)}$ ) and in the presence of phosphocitrate $(\mathrm{O})$.

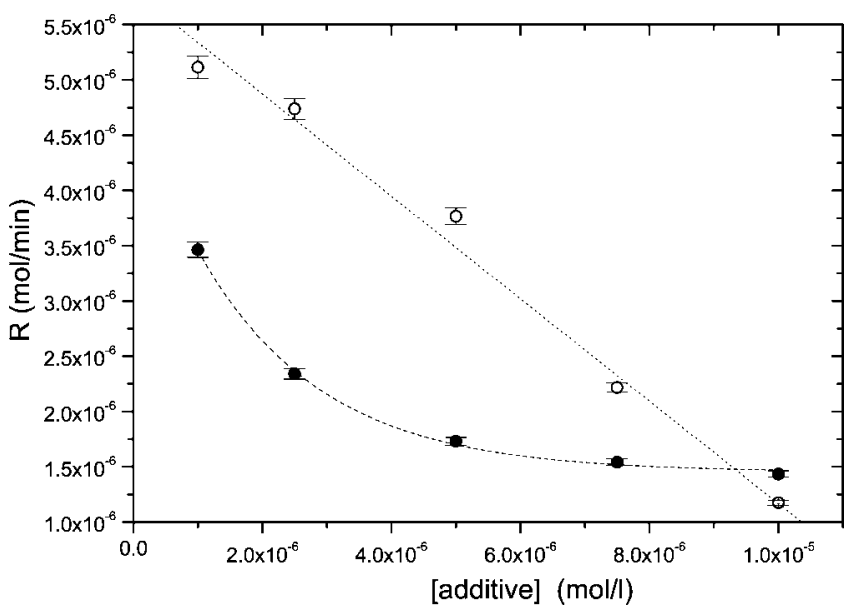

Figure 6. Dependence of the initial rates of spontaneous precipitation of struvite in synthetic wastewater solutions, on the additive concentration, $\mathrm{pH} 8.50,25^{\circ} \mathrm{C}$, and supersaturation $\Omega=4.864, \sigma=0.694$ : in the presence of citrate $(\bullet)$ and in the presence of phosphocitrate $(\bigcirc)$.

the presence of $1 \mu \mathrm{M}$ citrate and $1 \mu \mathrm{M}$ phosphocitrate, are summarized in Tables 2 and 3, respectively.

The induction times preceding precipitation were found to be inversely proportional to the solution supersaturation, as can be seen in Figure 1, in which the variation of the induction time as a function of the solution supersaturation (stability diagram) is shown in the presence of citrate and phosphocitrate and when no additives are present.

As may be seen in Figure 1, the presence of $1 \mu \mathrm{M}$ phoshocitrate did not result in significantly different induction times in comparison with the control solutions. In the presence of citrate, however, it may be clearly seen in Figure 1 that the onset of struvite precipitation was delayed.

In homogeneous precipitation, the dependence of the induction time on the solution supersaturation is given by $^{21}$

$$
\log \tau=\log A_{\mathrm{sp}}+\frac{B}{(\log \Omega)^{2}}
$$

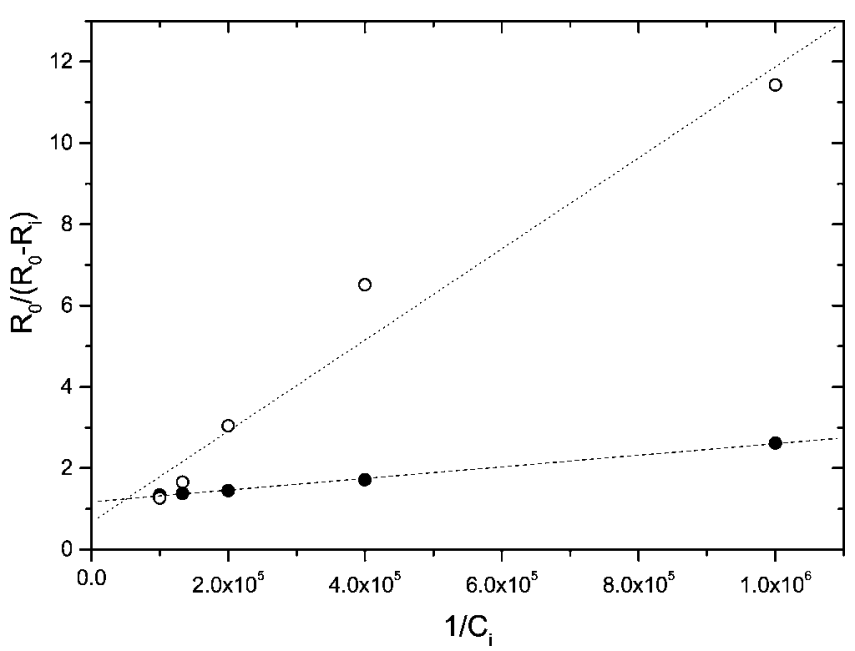

Figure 7. Langmuir adsorption isotherms applied to struvite crystal growth in the presence of citrate (-) and in the presence of phosphocitrate $(O)$.

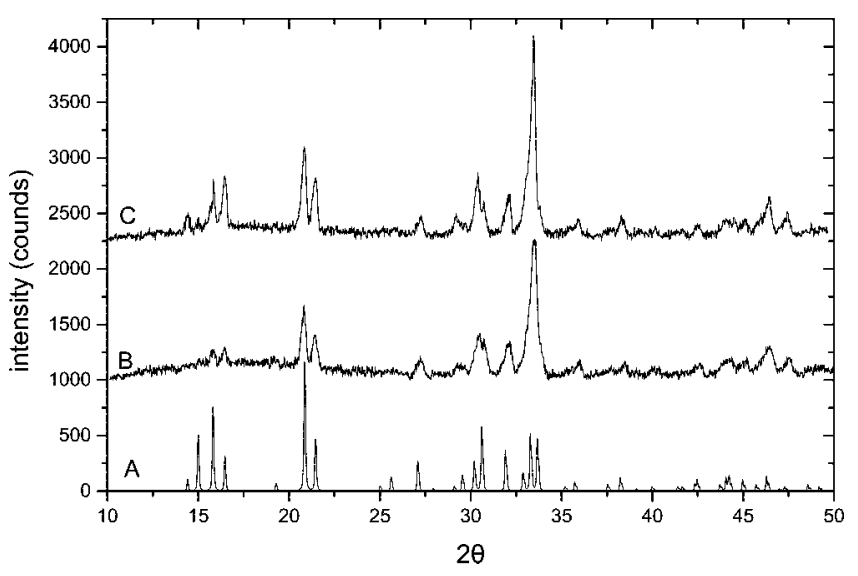

Figure 8. Powder X-ray diffractıpatterns from (A) reference pattern file 15-762 for synthetic struvite; (B) struvite precipitated spontaneously from SWW at constant supersaturation in the presence of citrate; (C) struvite precipitated spontaneously from SWW at constant supersaturation in the presence of phosphocitrate.

where $A_{\mathrm{sp}}$ and $B$ are constants according to the classical nucleation theory and $B$ is given by eq 6

$$
B=\frac{\beta v_{m}^{2} \gamma_{s}^{3}}{(2.303 k T)^{3}}
$$

where $\beta$ is a shape factor $(=32), v_{\mathrm{m}}$ is the molecular volume of struvite $\left(=7.99 \times 10^{-23} \mathrm{~cm}^{3}\right)$, and $\gamma_{\mathrm{s}}$ is the surface energy of the solid forming. The latter parameter may be calculated from plots of $\log \tau$ as a function of $(\log \Omega)^{-2}$ according to eq 5 .

In Figure 2, the dependence of the measured induction time on the solution supersaturation in a logarithmic form according to eq 5 is presented. The resulting intersecting straight line segments are considered to define the supersaturation regions in which precipitation is predominantly homogeneous (steeper part) and mainly heterogeneous (less steep segment). ${ }^{21}$ In the presence of phosphocitrate, only one part of the line was found. From the slope of the steep lines, the value of surface energy of the forming nucleus was calculated and found to be equal to $25.1 \mathrm{~mJ} \mathrm{~m}^{-2}$ was calculated for the struvite in the presence of $1 \mu \mathrm{M}$ of citrate and $15.3 \mathrm{~mJ} \mathrm{~m}^{-2}$ for the struvite in the presence of $1 \mu \mathrm{M}$ of phosphocitrate. It should be noted that the respective 

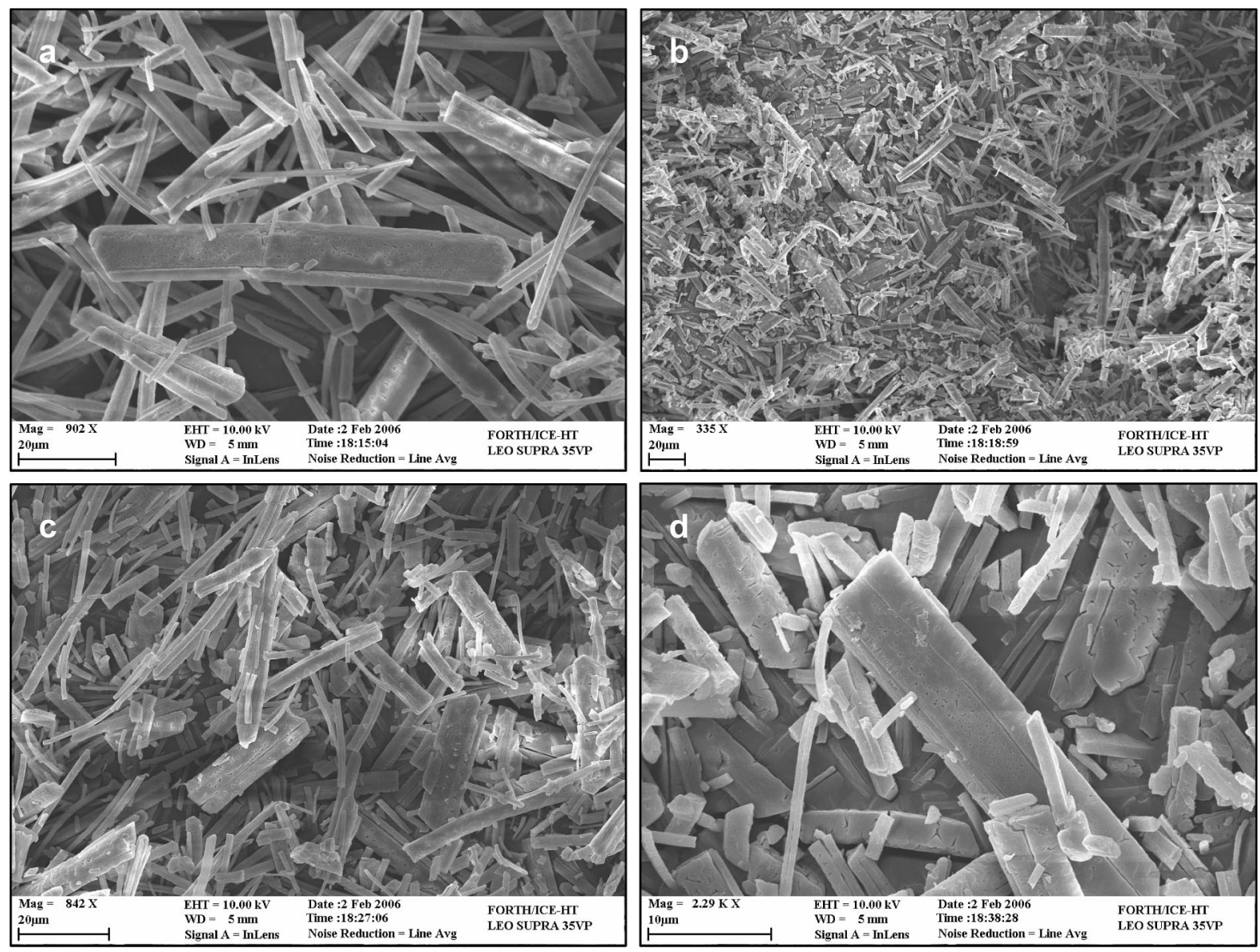

Figure 9. Scanning electron micrographs of struvite crystals precipitated in synthetic wastewater solution in the presence of (a) 2.5, (b) 5.0, (c) 7.5, and (d) $10.0 \mu \mathrm{M}$ citrate.

value calculated for the surface energy of the control system (no additive) was $15.5 \mathrm{~mJ} \mathrm{~m}^{-2}$.

The relationship between the induction time $\tau$ and the initial concentration of the supersaturated solution according to the Christiansen-Nielsen semiempirical relationship is ${ }^{22}$

$$
\tau=k_{p}[\mathrm{Mg}]_{0}^{1-p}
$$

where $k_{\mathrm{p}}$ is a constant and $p$ is an integer indicative of the size of the critical nucleus. Logarithmic plots according to eq 7 for the two types of experiments are shown in Figure 3. From the slope of those logarithmic plots, the indicative number for the size of the critical nucleus was calculated.

As may be seen from Figure 3, the slope in the presence of phosphocitrate is steeper for the corresponding one in the absence of additive, yielding values of $p=11$ and $p=15$ for the size of the critical nucleus, respectively. The steepest slope, suggesting a larger size for the critical nucleus $(p=21)$, was found for the solutions in the presence of citrate.

The rates of precipitation, $R_{\mathrm{p}}$, in all cases were found to depend strongly on the relative solution supersaturation. The kinetics results were fitted to the semiempirical power law

$$
R_{p}=k_{\mathrm{sp}} \sigma^{n}
$$

where $k_{\mathrm{sp}}$ is the apparent rate constant for the spontaneously precipitating struvite, $\sigma$ the relative supersaturation, and $n$ the apparent order for the process. The dependence of the measured rates as a function of the relative solution supersaturation is shown in Figure 4.
Plots of the rates of precipitation of struvite as a function of the relative supersaturation showed a high-order dependence $(n>2)$ over the range of supersaturations investigated, as may be seen in Figure 4. This dependence is indicative of a surface-controlled mechanism. High apparent orders have been reported for a number of sparingly soluble salts, the crystal growth of which is clearly controlled by surface diffusion. ${ }^{23}$ Kinetics plots provide mechanistic information concerning the rate determining step for the integration of growth units into the growing supercritical nuclei. The integration involves the following main steps: mass transport from bulk solution, adsorption onto the crystal surface following partial dehydration, and transport by diffusion onto the surface and integration into kinks, the active sites with the least energy. Mass transport control is marked by a first-order dependence of the rate of precipitation on the solution supersaturation. For both cases reported here, the presence of both additives caused reduction of the rates of struvite precipitation. In the presence of citrate, the rate reduction was stronger as compared with the respective rate in the presence of phosphocitrate.

In the second set of experiments, the concentration of citrate and phosphocitrate used ranged from 1 to $10 \mu \mathrm{M}$. All experiments were done at the same supersaturation $\Omega$ with respect to struvite. The experimental conditions and the results obtained are summarized in Table 4. The relative inhibition was calculated from the eq 9

$$
\text { relative inhibition }=\frac{R-R_{i}}{R} \cdot 100 \%
$$


where $R$ and $R_{i}$ are the crystal growth rates measured in the absence of additive and in the presence of additive (citrate or phosphocitrate), respectively.

The induction times and the initial precipitation rates measured were affected significantly by the concentration of the additive. Plots of the induction time and of the initial precipitation rates as a function of the additive concentration for citrate and phosphocitrate for the struvite formation in supersaturated SWW solutions are presented in Figures 5 and 6.

For the same supersaturation, it was found that the induction times were proportional to the additive concentration, whereas the initial precipitation rates were inversely proportional to the additive concentration. Comparison of the kinetics obtained in the presence of the two additives showed that citrate delayed the onset of struvite precipitation more than the phosphocitrate did at all concentrations tested. The rates of precipitation were in all cases lower in the presence of citrate. However, although a limiting rate was reached in the presence of $5 \mu \mathrm{M}$ of citrate for the phosphocitrate, the rate of precipitation of struvite was found to continuously decrease with increasing additive concentration, as may be seen in Figure 6. At concentration of 10 $\mu \mathrm{M}$, the rate of precipitation of struvite in the presence of either of the two additives tested was the same.

The inhibition effectiveness of the two additives tested here may be attributed to their adsorption on the crystal surface and succeeding blocking of the active crystal growth sites. The difference in the adsorption strength and site of the additives may be investigated from the kinetics analysis according to the model in which adsorption is assumed to be described by the Langmuir model. The model assumes a steady-state adsorption/ desorption in the absence of interactions between growth sites, and the Langmuir adsorption isotherm is given in eq $10:^{24}$

$$
\frac{R}{R-R_{i}}=\frac{1}{\mathrm{~A}^{\prime}}+\frac{\mathrm{B}^{\prime}}{\mathrm{A}^{\prime}} \frac{1}{C_{i}}
$$

where $A^{\prime}$ and $B^{\prime}$ constants.

Plots according to eq 10 are shown in Figure 7 . The linearity of the plots for citrate and phoshocitrate suggested that the two additives tested were adsorbed at the active struvite growth sites.

From eq 10, 1/ B' is equal to the ratio of the specific rate constants of adsorption, $k_{\text {ads }}$, over the specific rate constant for desorption, $k_{\mathrm{des}}, k_{\mathrm{ads}} / k_{\mathrm{des}}=k_{\mathrm{aff}}$. This ratio is defined as the affinity constant ${ }^{25}$ and may be calculated from the slope of the linear fit of the kinetics data according to eq 10 . The value of the affinity constant, although it lacks physical meaning, may be considered as a measure for the affinity of the adsorbate for the adsorbent. The value of the affinity constant calculated from the results of the precipitation kinetics of struvite in the presence of citrate ions was found equal to $8.2 \times 10^{5}$. The respective value in the presence of phosphocitrate was calculated to be equal to $0.6 \times 10^{5}$. The difference between the two values reflects the relative difference of affinity, which each of the two additives has for the precipitating mineral. The molecular geometry may be considered as a key factor in the relative efficiency of inhibition by the two compounds. Moreover, the fact that the intercept is greater than 1 for citrate may be interpreted as its partial ability to inhibit the crystal growth of struvite and may affect the morphology. On the contrary, the intercept for phosphocitrate, less than 1 , suggested that this compound may inhibit struvite crystal growth at concentrations lower than those needed for monolayer coverage of the solid. ${ }^{24}$

In all experiments, struvite precipitated exclusively, as may be seen from the powder X-ray diffraction pattern shown in
Figures 8 . The BET surface area of the precipitated struvite was found to be about $4 \mathrm{~m}^{2} / \mathrm{g}$ in the presence of citrate and $2 \mathrm{~m}^{2} / \mathrm{g}$ in the presence of phosphocitrate.

The morphology of the precipitated struvite crystals in the presence of citrate and phosphocitrate is shown in the scanning electron micrographs in Figures 9 and 10, respectively. In the presence of either citrate or phosphocitrate, the precipitated struvite crystals were prismatic crystals, similar to those precipitated at experiments in the absence of additive. Over the entire range of additive concentration examined, the precipitated struvite crystals had the same morphology.

The only difference between the crystals formed in the presence of citrate and phosphocitrate was their respective size. As may be seen from the micrographs shown in Figure 10, in the presence of phosphocitrate, the needlelike struvite crystals precipitated were grown along the $c$ axis, whereas the crystals precipitated in the presence of citrate exhibited shorter length and larger width. In both cases, because of the precipitation retardation, some larger and better-shaped crystals were formed in comparison with the crystals obtained by spontaneous precipitation in the absence of additives.

Adsorption of additives is expected to affect the surface charge of the crystals forming in the supersaturated solutions. The potential determining ions for struvite are $\mathrm{Mg}^{2+}, \mathrm{NH}_{4}{ }^{+}$, and $\mathrm{PO}_{4}{ }^{3-}$, i.e. the lattice ions of the solid. ${ }^{26}$ The surface charge of struvite particles in synthetic wastewater solution was calculated from electrophoretic mobility measurements of struvite suspensions as a function of the concentration of citrate and of phosphocitrate at constant $\mathrm{pMg}$ (equal to 2.5). The results obtained are shown in Figure 11. As may be seen, struvite particles showed a negatively charged surface in the presence of either citrate or phosphocitrate. It is interesting to note that in the absence of the additives, the negative potential of the struvite particles was very close to the respective value measured in $0.01 \mathrm{M} \mathrm{NaCl}$ at the same pMg value. ${ }^{27}$ The zeta-potential values remained virtually unchanged with increasing additive concentration in the struvite suspensions.

It should be noted that citrate and phosphocitrate bear different anionic charges at the test $\mathrm{pH}$ (8.50). Citrate (citric acid has $\mathrm{pK}_{\mathrm{a}}$ values of $3.13,4.76$, and 6.40 for the three-COOH groups) and possesses a 3- charge, whereas phosphocitrate (phosphocitric acid has $\mathrm{pK}_{\mathrm{a}}$ values of of $<2.00$ (for $-\mathrm{P}-\mathrm{OH}$ ), 3.67 (for $\beta$-COOH), 5.15 (for $\alpha-\mathrm{COOH}$ ), 7.69 (for $-\mathrm{P}-\mathrm{OH}$ ), and $>13.00$ $($ for $\alpha-\mathrm{COOH}))^{28}$ possesses a $4-$ charge at $\mathrm{pH} 8.50$. It is therefore not unlikely that the increased anionic charge on phosphocitrate, and by consequence, its weaker interaction with the negative struvite surface (vide supra), is linked to its reduced inhibitory activity compared to that of citrate.

\section{Conclusions}

In the present work, the effect of citrate and phosphocitrate ions on the kinetics and the morphology of the spontaneous precipitation of magnesium ammonium phosphate hexahydrate in synthetic wastewater supersaturated solutions was investigated. Both citrate and phosphocitrate ions in SWW supersaturated with respect to struvite were found to be effective inhibitors. The experimental conditions were selected so that struvite precipitated spontaneously. The induction times preceding struvite precipitation increased in the presence of $1 \mu \mathrm{M}$ citrate. In the presence of phosphocitrate, however, and at the same concentration, almost no effect was measured on the induction time, which in all cases decreased with increasing supersaturation. In the presence of $1 \mu \mathrm{M}$ citrate, the surface energy of the struvite forming was 

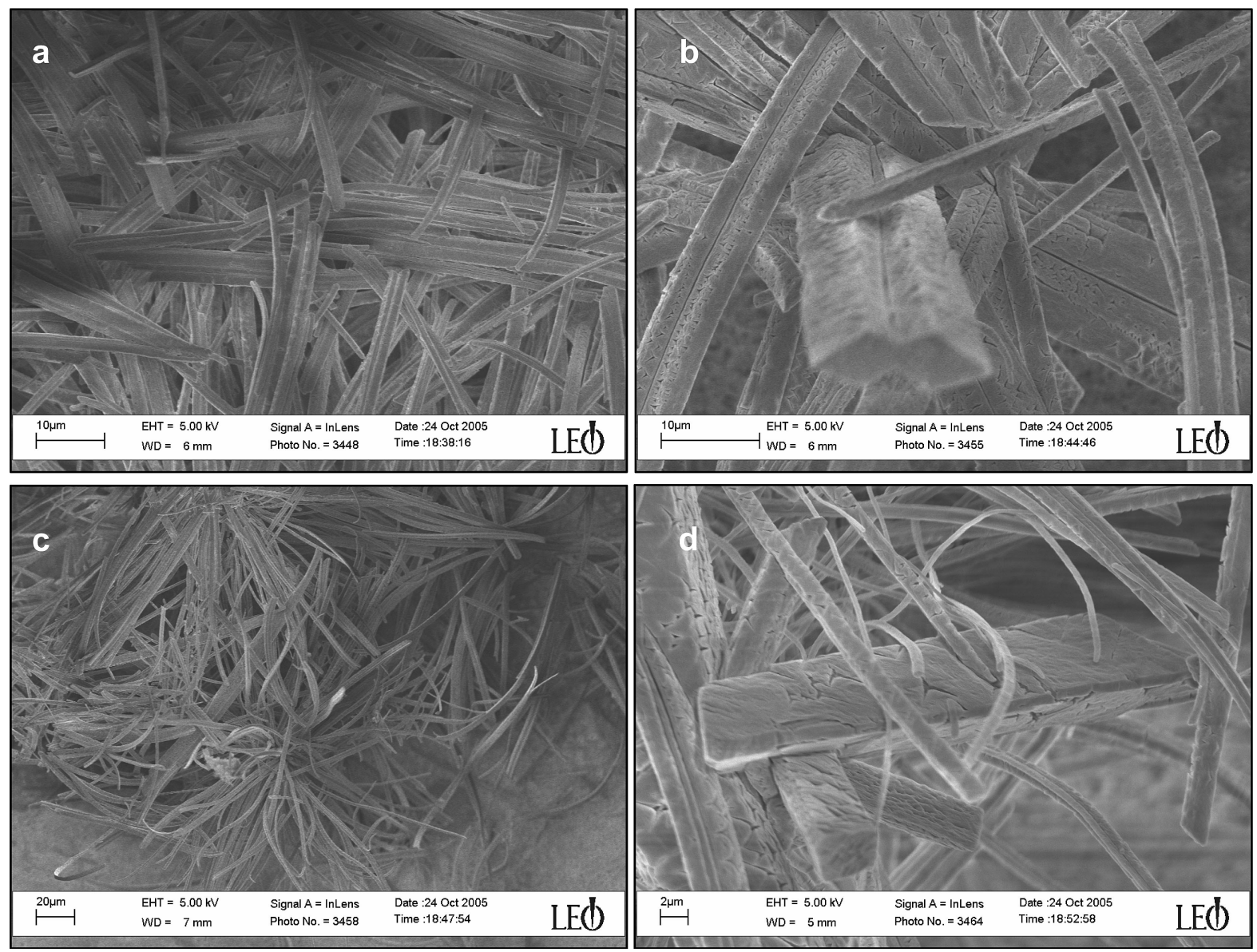

Figure 10. Scanning electron micrographs of struvite crystals precipitated in synthetic wastewater solution in the presence of (a) 2.5, (b) 5.0, (c) 7.5, and (d) $10.0 \mu \mathrm{M}$ phosphocitrate.

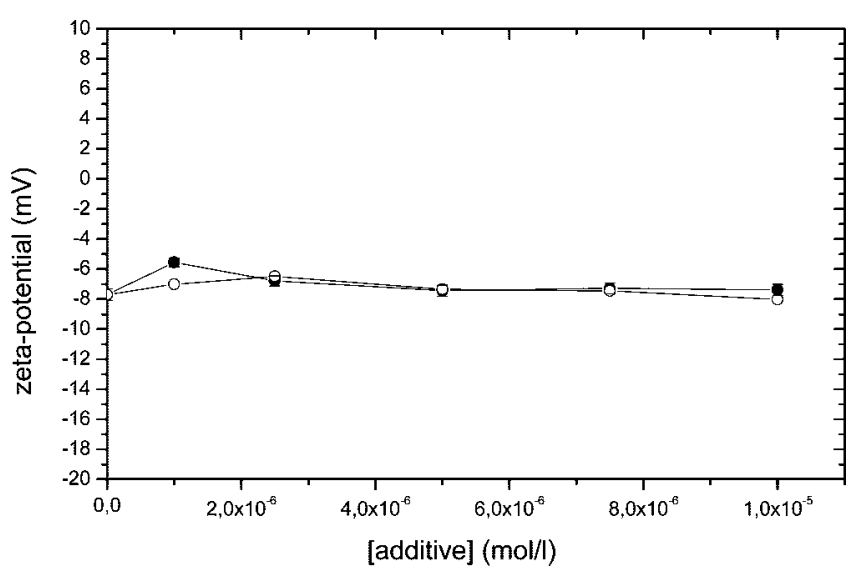

Figure 11. Zeta-potential plots of struvite particles in synthetic wastewater solution in the presence of citrate $(-)$ and in the presence of phosphocitrate $(O)$.

calculated to be equal to $25.1 \mathrm{~mJ} \mathrm{~m}^{-2}$, whereas for phosphocitrate, it was found to be equal to $15.3 \mathrm{~mJ} \mathrm{~m}^{-2}$. The rates of struvite precipitation from supersaturated SWW decreased in the presence of both additives examined. The rates decreased continuously in the presence of phosphocitrate over the concentration range between 1 and $10 \mu \mathrm{M}$. In the case of citrate, a plateau was obtained for the rate of struvite precipitation at a concentration of $5 \mu \mathrm{M}$, after which the rate was constant for increasing citrate concentration. The struvite crystals precipitated in the presence of both additives from synthetic wastewater showed the same morphology as in their absence. Differences, however, were found in their sizes. Shorter and wider crystals were formed in the presence of citrate ions. Future studies will focus on the dilineation of which moieties on the phosphocitrate molecule are responsible for struvite inhibition. This is now possible because of the availability of novel phosphocitrate derivatives, based on selective esterification of either the phosphate of the carboxylate moieties.

Acknowledgment. Financial support through the PENED 2001 Programme Contract M413, by the General Secretariat for Research and Technology, Ministry of Development, is gratefully acknowledged. Technical and instrumental support from FORTH/ICE-HT is greatly appreciated.

\section{References}

(1) (a) Whitaker, A.; Jeferey, J. W. Acta Crystallogr., Sect. B 1970, 26, 1429. (b) Abbona, F.; Calleri, M.; Ivaldi, G. Acta Crystallogr., Sect. $B$ 1984, 40, 223. (c) Ferraris, G.; Fuess, H.; Jiswig, W. Acta Crystallogr., Sect. B 1986, 42, 253. (d) Whitaker, A.; Jeferey, J. W. Acta Crystallogr., Sect. B 1970, 26, 1440.

(2) (a) de-Bashan, L. E.; Bashan, Y. Water Res. 2004, 38, 4222. (b) Jaffera, Y.; Clarkb, T. A.; Pearceb, P.; Parsons, S. A. Water Res. 2002, 36, 1834.

(3) (a) Mohajit, X.; Bhattarai, K. K.; Taiganides, E. P.; Yap, B. C. Biol. Wastes 1989, 30, 133. (b) Doyle, J. D.; Philip, R.; Churchley, J.; Parsons, S. A. Trans. IChemE 2000, 78B, 480. (c) Maqueda, C.; Perez Rodriguez, J. L.; Lebrato, J. Water Res. 1993, $28,411$.

(4) (a) Horenstein, B. K.; Hernandez, G. L.; Rasberry, G.; Crosse, J. Water Sci. Technol. 1990, 22, 12-183. (b) Wrigley, T. J.; Webb, K. M.; Venkitachalm, H. Bioresour. Technol. 1992, 41, 117. (c) Battistoni, 
P.; De Angelis, A.; Prisciandaro, M.; Boccadoro, R.; Bolzonella, D. Water Res. 2002, 36, 1927.

(5) (a) Demadis, K. D.; Stathoulopoulou, A. Mater. Perform. 2006, 45 (1), 40. (b) Demadis, K. D.; Katarachia, S. D. Phosphorus, Sulfur Silicon Relat. Elem. 2004, 179, 627.

(6) (a) Kuzmanovski, I.; Trpkovska, M.; Soptrajanov, B. J. Mol. Struct. 2005, 833, 744-747. (b) Sternberg, K.; Greenfield, S. P.; Williot, P.; Wan, J J. Urol. 2005, 174, 1711. (c) Grases, F.; Sohnel, O.; Vilacampa, A. I.; March, J. G. Clin. Chim. Acta 1996, 244, 45.

(7) Sperin, M. W.; Rogers, K. Br. J. Urol. 1998, 82, 781.

(8) (a) Demadis, K. D.; Sallis, J. D.; Raptis, R. G.; Baran, P. J. Am. Chem. Soc. 2001, 123, 10129. (b) Demadis, K. D. Inorg. Chem. Commun. 2003, 6, 527. (c) Sun, Y.; Reuben, P.; Wenger, L.; Sallis, J. D.; Demadis, K. D.; Cheung, H. S. Front. Biosci. 2005, 10, 803. (d) Sallis, J. D.; Demadis, K. D.; Cheung, H. S. Curr. Rheumatol. Rev. 2006, 2, 95. (e) Sallis, J. D. In Calcium Phosphates in Biological and Industrial Systems; Amjad, Z., Ed.; Kluwer Academic Publishers: New York, 1998; Chapter 8, p 173

(9) (a) Williams, G.; Sallis, J. D. Calcif. Tissue Int. 1982, 34, 169. (b) Tew, W. P.; Mahle, C.; Benavides, J.; Howard, J. E.; Lehninger, A. E. Biochemistry 1980, 19, 1983.

(10) Sharma, V. K.; Johnsson, M.; Sallis, J. D.; Nancollas, G. H. Langmuir 1992, 8, 676

(11) Cheung, H. S.; Kurup, I. V.; Sallis, J. D.; Ryan, L. M. J. Biol. Chem. 1996, 271, 28082.

(12) (a) Sallis, J. D.; Parry, N. F. G.; Meehan, J. D.; Kamperman, H.; Anderson, M. E. Scanning Microsc. 1995, 9, 127. (b) Wierzbicki, A.; Sikes, C. S.; Sallis, J. D.; Madura, J. D.; Stevens, E. D.; Martin, K. L. Calcif. Tissue Int. 1995, 56, 297.

(13) Sallis, J. D.; Juckes, W.; Anderson, M. E. In Mineral Scale Formation and Inhibition; Amjad, Z., Ed.; Plenum Press: New York, 1995;Chapter $8, \mathrm{p} 87$.

(14) Sallis, J. D.; Thomson, R.; Rees, B.; Shankar, R. J. Urol. 1998, 140, 1063.
(15) Wierzbicki, A.; Sallis, J. D.; Stevens, E. D.; Smith, M.; Sikes, C. S. Calcif. Tissue Int. 1997, 61, 216.

(16) Bates, R. G. pH Determination; Wiley: New York, 1973.

(17) Williams, G.; Sallis, J. D. Anal. Biochem. 1980, 102, 365.

(18) (a) Battistoni, P.; Pavan, M.; Prisciandaro, M.; Cecchi, F. Water Res. 2000, 34, 3033. (b) Battistoni, P.; De Angelis, A.; Pavan, M.; Prisciandaro, M.; Cecchi, F. Water Res. 2001, 35, 2167. (c) Nelson, N. O.; Mikkelsen, R. D.; Hesterberg, D. L. Bioresour. Technol. 2003, 89, 229. (d) Doyle, J. D.; Parsons, S. A. Wat. Res. 2002, 36, 3925.

(19) (a) Koutsoukos, P. G.; Valsami-Jones, E.; In Phosphorus Removal Technologies from Water and Wastewater; IWA Publications: London, 2003. (b) Kofina, A. N.; Koutsoukos, P. G. Cryst. Growth Des. 2005, 5,489 .

(20) Mineql + A Chemical Equilibrium Modeling System; Version 4.0; Environmental Research Software: Hallowell, ME, 1998.

(21) Mullin, J. W. Crystallization, 4th ed.; Butterworths- Heinemann: Oxford, U.K., 2001.

(22) Nielsen, A. E. Kinetics of Precipitation, Pergamon: Oxford, 1964.

(23) Söhnel, O.; Garside, J. Precipitation, Butterworth- Heinemann: Oxford, 1992.

(24) Nancollas, G. H.; Zawacki, S. J. In Industrial Crystallization, Proceedings of the 9th Symposium on Industrial Crystallization, The Hague, The Netherlands, Sept 25-28, 1984; Jancic, S. J., de Jong, E. J. Eds.; Elsevier: Amsterdam, 1984;Vol. 84.

(25) Amjad, Z.; Koutsoukos, P. G.; Nancollas, G. H. J. Colloid Interface Sci. 1984, 101, 250 .

(26) Lyklema, J. Fundamentals of Interface and Colloid Science; Academic Press: London, 1995

(27) Bouropoulos, N. C.; Koutsoukos, P. G. J. Cryst. Growth 2000, 213, 381 .

(28) Ward, L. C.; Shankar, R.; Sallis, J. D. Atherosclerosis 1987, 65, 117.

(29) Turhanen, P.; Demadis, K. D.; Peräniemi, S.; Vepsäläinen, J. J. J. Org. Chem. 2007, 72, 1468.

\section{CG0603927}

